Literatura y Lingüística $\mathrm{N}^{\circ} 25$

ISSN $0716-5811$ / pp. 17-37

\title{
Aimé Césaire y Tropiques: comienzos literarios en el Caribe francés*
}

\author{
Florencia Bonfiglio $^{* *}$
}

\section{Resumen}

Este trabajo aborda los comienzos de Aimé Césaire en el contexto de fundación de un sistema literario en las Antillas francesas, concentrándose especialmente en su programa de literatura martiniqueña delineado a través de la revista Tropiques (1941-1945). Como proponemos, la carrera intelectual de Césaire y el proyecto efectivamente llevado a cabo por la revista son un índice de las posibilidades de desarrollo de una literatura martiniqueña tanto como de las dificultades a los que ésta (aún hoy) está sometida, resultantes de los intercambios asimétricos determinados por la lógica de los circuitos coloniales. En tal contexto, la acción y el apoyo de intelectuales e instituciones metropolitanas han sido cruciales. Fue, en efecto, fundamentalmente por la mediación de los surrealistas franceses como el grupo de Tropiques estableció una intercomunicación con movimientos y escritores latinoamericanos y antillanos. Y fue, a su vez, gracias al apoyo de figuras 'faro' como Sartre o Breton, como Césaire alcanzó prestigio y reconocimiento como poeta e intelectual.

Palabras clave: Aimé Césaire, comienzos, Antillas francesas, Tropiques

\section{Aimé Césaire and Tropiques: Literary Beginnings in the French Caribbean}

\begin{abstract}
This paper deals with Aimé Césaire's beginnings in the context of foundation of a literary system in the French Antilles, by especially focusing on his program of a Martinican literature as delineated in his review Tropiques (1941-1945). According to our reading, Césaire's intellectual career and the project actually carried out by the review are an example of the concrete possibilities of development of a Martinican literature as well as of the difficulties this faces (even today), resulting from asymmetrical exchanges determined by the logic of colonial circuits. In such context, the action and support offered by metropolitan institutions and intellectuals have been crucial. It was mainly due to the contacts established with the French surrealists that Tropiques started its intercommunication with Antillean and Latin American movements and writers. It was also thanks to key figures such as Sartre and Breton that Césaire achieved prestige and acknowledgement as a poet and intellectual.
\end{abstract}

Key words: Aimé Césaire, beginnings, French Antilles, Tropiques

Recibido: 10-01-2012Ａceptado: 26-01-2012

* La investigación forma parte de la tesis de Doctorado sobre las reescrituras de La tempestad de Shakespeare en Latinoamérica y el Caribe. Universidad de Buenos Aires (UBA).

** Dra. en Letras. Universidad Nacional de La Plata, Argentina. flobonfiglio@hotmail.com 


\section{De la isla a la metrópolis: estudiantes negros en París}

Si todos los inicios literarios en condiciones de dependencia cultural, como argumenta Said, resultan dificultosos (1985: 381), para Aimé Césaire (1913-2008), un afrodescendiente nacido en una isla colonial del Caribe francés como la Martinica, el comienzo en París en la época de las vanguardias no podía ser más dramático. No solo se dirigía al centro por excelencia de la cultura letrada sin una tradición local que lo respaldara; además, se dirigía allí nutrido de la misma tradición francesa y hablando la misma lengua: para sobresalir, la originalidad debía ser radical.

Por esos años, para los negros provenientes de las colonias antillanas francesas, inglesas u holandesas, el problema de los comienzos era claramente mayor que el de los negros latinos y norteamericanos, incluso mayor que el de otros negros antillanos, tanto los de las islas de colonización española -Cuba, Puerto Rico, República Dominicana-, como los de Haití, ex-colonizada por Francia. No nos referimos solo al factor estructural del racismo de la intelligentsia, la abierta negrofobia aún perceptible avanzado el siglo XX. La dificultad radicaba fundamentalmente en el hecho de que los jóvenes como Césaire no contaban con un sistema literario local, siquiera blanco, afrancesado y racista: en las Antillas francófonas no existía (como tampoco en las anglófonas u holandesas) una ciudad letrada, un 'elenco intelectual dirigente' en la formulación de Rama (1995) para el caso latinoamericano, que a lo largo del tiempo hubiera posibilitado la institucionalización de la literatura y, eventualmente, los comienzos de los escritores negros cuando las ciudades se politizaran y hasta revolucionaran.

En el área francófona, por el contrario, la primera universidad fue creada en Haití, independizada de Francia en 1804, recién en 1920. Fue la instalación de sociedades de plantación y ciudades-'factorías' (que incluso cambiaron de dueño en repetidas oportunidades), bajo un capitalismo más avanzado y más subdesarrollante, y poderes imperiales fuertemente centralizados y antiintegracionistas, lo que explica que tampoco en el área anglófona pudieran surgir antes de mediados del siglo XX instituciones y grupos intelectuales locales que impulsaran una actividad literaria más organizada. ${ }^{1}$ Aún a mediados del siglo XX (y a

1 Hasta mediados del siglo XX, por ejemplo, sólo existía en las colonias francesas una escuela de Derecho (creada en 1882) en la Martinica, y fue recién en los años 60 cuando se ampliaron los estudios universitarios, incluyendo la formación en Letras.

(18)


causa también de la destrucción de Saint-Pierre y sus instituciones por la erupción del volcán Pelée en 1902), la enseñanza secundaria en Martinica sólo era ofrecida en Fort-de-France y en unos pocos establecimientos, entre los cuales el Liceo Schœlcher era el más prestigioso. Fue allí donde, beneficiado con una beca, estudió Césaire, hasta ser nuevamente becado para cursar estudios superiores en Francia. Como señalaba Michel Leiris en uno de los primeros estudios dedicados a la cultura de las Antillas francesas, Contacts de civilisations en Martinique et en Guadeloupe (1955), el martiniqueño pertenecía a las primeras generaciones de negros que, provistos "de un cierto capital de cultura europea", se dirigían a París para obtener una educación académica. Salvo excepciones, esta había sido inaccesible a los afrodescendientes apenas liberados de la esclavitud, y por mucho tiempo la clase mulata había sido prácticamente la única en alcanzar la universidad, ya que a los blancos criollos esta "les parecía no ser de gran utilidad para desempeñarse en las vías ya trazadas que les ofrecía el cultivo y las industrias de la caña así como el comercio y la banca". (2008: 74). ${ }^{2}$

Se trataba, sobre todo para los negros, de un medio hostil al desarrollo cultural y a la formación de carreras intelectuales, artísticas o literarias. Césaire, lector voraz desde su infancia, se dirigió a París munido de una instrucción francesa que había intentado superar con cuanta lectura extraescolar le fue accesible (no demasiada, ya que apenas había librerías, el pedido de libros resultaba muy costoso, y la Biblioteca Schœlcher, prácticamente la única existente, "no era sino una biblioteca colonial... Uno podía encontrar, con seguridad, libros de Victor Hugo y de Leconte de Lisle, pero ni siquiera creo que tuvieran una obra completa de Baudelaire", recordaría Césaire en una entrevista con Jacqueline Leiner (2008 [1975]: 382). Durante sus años adolescentes, había habido en Fort-de-France, sin embargo, cierta actividad intelectual renovadora, la cual intentaba distinguirse de la de aquellos 'asimilados' de la élite, admiradores incondicionales de la cultura metropolitana y "virtuosos de la lengua francesa", como los llama Leiris, tales como Victor Duquesnay o Daniel Thaly (2008 [1955]: 98). En 1927, había aparecido la revista Lucioles. Journal de l'éffort littéraire Martinique, "el primer periódico literario de las Antillas francesas que se propuso trabajar en un sentido propiamente antillano" (Leiris, 2008 [1955]: 80), fundado por el poeta

2 De aquí en más, excepto en aquellos casos en que, como se consigna en la Bibliografía, utilizamos traducciones ya existentes, las versiones en español de los originales en francés nos pertenecen. 
negro Gilbert Gratiant, maestro de Césaire y del guyanés Léon Gontran Damas en el Liceo Schœlcher (con quienes colaboraría luego en París en la revista L'étudiant noir), y, entre otros, el escritor blanco criollo Auguste Joyau y el metropolitano Octave Mannoni. El grupo de Lucioles organizaba 'matinées littéraires' y generó cierto movimiento local; su revista se ocupaba de la producción martiniqueña y de la actualidad intelectual y artística metropolitana. Por la misma época, aparecía además la Revue de la Martinique (1926-1939), con un marcado interés por la historia y la política local, cuyo animador fue el profesor de filosofía, periodista y militante socialista Jules Monnerot (padre de Jules-Marcel, uno de los creadores, en París, de la revista Légitime Défense).

Aunque Lucioles no tuviera un sesgo ideológico contestatario, como publicación literaria con cierto alcance en las colonias vecinas de Guadalupe y la Guyana, fue precursora de Tropiques, la revista que fundaría Césaire a su retorno de París. Sin embargo, si se compara el papel de Lucioles en la formación de una literatura franco-antillana con el de la contemporánea Revue Indigène publicada en Haití (julio 1927- febrero 1928), se comprueban las dificultades de los martiniqueños para generar un movimiento relevante in situ y fundar las bases de un sistema literario local que, en contacto con los movimientos contemporáneos antillanos y americanos, diera voz a los negros. La situación de aislamiento cultural de la élite intelectual martiniqueña respecto del resto de las Antillas y de América era total. El contacto, además, no podía hacerse de modo tan directo (como en Haití), "era necesario pasar por París para ir de Fort-de-France a La Habana, a Caracas o a Washington" (Laroche, 1995: 524). Mientras tanto, en Haití surgía un movimiento 'indigenista', de valorización de las raíces africanas y las tradiciones populares, que se ponía a la cabeza de la producción antillana en francés. Pero los martiniqueños, como explicaría Césaire en varias entrevistas, no recibían tampoco 'influencias' del indigenismo haitiano (ni del negrismo cubano), porque entonces no los conocían, aunque compartieran con ellos la 'negritud', la historia colonial francesa y el uso de una misma lengua que auspiciaba los intercambios. La independencia de Haití de Francia había revertido en una invisibilización de la primera República Negra: como recordaría Césaire, Haití tenía "mala reputación" en la Martinica (Leiner, 2003: 49).

En dicho contexto, el París de entreguerras se presentaba como un espacio fértil para las coaliciones intelectuales y, especialmente, el 'internacionalismo negro'. Allí, en efecto, luego de la bilingüe Revue du Monde Noir (1931-1932) fundada por el haitiano Sajous y las hermanas marti-

$+20$


niqueñas Jane y Paulette Nardal, un grupo de estudiantes martiniqueños publicarían el primer (y único) número de Légitime Défense en 1932. Entre sus jóvenes redactores, se contaban el mencionado Jules-Marcel Monnerot, René Ménil -quien de vuelta en la isla fundaría Tropiques junto con Césaire- y Étienne Léro; ${ }^{3}$ más tarde, estos se agruparían en torno de Césaire y L'Étudiant noir (1935), donde la "Negritud" sería por primera vez enunciada. Ambas revistas, en la metrópolis, fundarían las bases de una literatura martiniqueña, en especial, sus principios anti-coloniales y su afiliación con la escritura negra más militante.

Légitime Défense no sólo inauguraba el 'surrealismo antillano', como posteriormente celebraría el metropolitano Leiris (2008 [1955]: 99), sino que establecía el programa de un sistema literario diferenciado, aunque de modo rudimentario y-dadas las condiciones coloniales- en un 'polo externo': abordaba una serie de temas particulares de las Antillas francesas 'asimiladas', daba voz a un conjunto de productores con conciencia de su papel como intelectuales negros martiniqueños y (a diferencia de la Revue du Monde Noir), interpelaba a un grupo más específico (y más disidente) de lectores en el campo literario francés: en principio, los estudiantes antillanos residentes en París, ${ }^{4}$ pero que podía extenderse al resto de los colonizados por Francia con actitudes anti-asimilacionistas y anti-colonialistas, lo cual sería el objetivo cumplido por Césaire con L'Étudiant noir, entre cuyos colaboradores se encontraron senegaleses como Léopold Sedar Senghor, Ousmane Socé, Birago Diop y guyaneses como Damas y Henri Eboué, además de aquellos martiniqueños mayores que habían formado parte de la Revue du Monde Noir, como Paulette Nardal y Gratiant.

El pasaje de esas primeras experiencias en la metrópolis a aquellas emprendidas de vuelta en la isla, con la fundación de la revista Tropiques, demuestra sin duda las tensiones y dificultades intelectuales del

3 Los tres habían colaborado en la Revue du Monde Noir. La lista de firmantes de Légitime Défense incluía también a Thélus Lero, Michel Pilotin, Maurice-Sabas Quitman, Auguste Thésée y Pierre Yoyotte. En la sección de poesía (la menos valiosa) colaboraba también Simone Yoyotte.

4 El número debía aparecer en L'Étudiant martiniquais, órgano de la Asociación de estudiantes martiniqueños en Francia (que con Césaire pasaría a ser L'Étudiant noir), pero el tono hizo que se excluyera a los redactores del panfleto, quienes decidieron publicar la revista independientemente (Malela, 2008: 123). Se planeaba de aparición trimestral e incluía publicidad de obras surrealistas (como el Manifesto "Contra el imperialismo", "órgano de la la Liga francesa contra la opresión colonial y el imperialismo y de la Sección francesa de la Liga Internacional contra el imperialismo y por la independencia de los pueblos coloniales", y libros recientemente aparecidos de Crevel, Breton, Tzara, etc.) (1932: 23-24). Realizaban, además, reclamos particulares respecto de la situación de los estudiantes martiniqueños en París. 
intercambio asimétrico. Ciertamente, la carrera literaria de Césaire es un claro ejemplo tanto de las posibilidades efectivas de una literatura martiniqueña como de los límites a los que esta (aún hoy) está sometida, puesto que la religación transnacional y los vínculos establecidos por los metropolitanos fueron cruciales para su desarrollo. Porque, en efecto, no bastaba con el apoyo del 'mundo negro'; tampoco fue por la publicación del Cuaderno de un retorno al país natal en París en 1939 como Césaire obtuvo un reconocimiento más allá de su círculo intelectual, sino por la posterior reedición bilingüe impulsada por André Breton en 1947 en Nueva York, ${ }^{5}$ que motivó una nueva edición francesa del Cahier (por Bordas) el mismo año, por supuesto acompañada del prefacio "Un grand poète noir", el cual había aparecido en varias revistas (entre ellas Tropiques de Césaire), luego del encuentro con el líder del Surrealismo. Tal encuentro en Fort-de-France, en 1941, había sido en verdad azaroso -caro al Surrealismo-, pero a partir de allí habían comenzado a establecerse vínculos estratégicos -el de Sartre sin duda el más fructífero- que posibilitarían el reconocimiento de Césaire y de la literatura afro-antillana en la metrópolis una vez finalizada la Segunda Guerra. A partir de entonces, de hecho, la 'Negritud' empezaría a obtener visibilidad como un movimiento transnacional y más unificado de lo que era. Las antologías, asimismo, colaborarían con su legitimación y difusión: Damas publicaba en 1947 su Poètes d'expression française en Du Seuil, y en 1948 aparecía la Antología de Senghor que, con el apoyo del famoso prefacio de Sartre, "Orfeo Negro", por primera vez suscitaba el interés de la crítica por la escritura de las colonias y, especialmente, por la figura de Césaire.

\section{Principios literarios en los Trópicos}

Desde su retorno a la Martinica en 1939, y su dirección de Tropiques -14 números publicados entre 1941 y 1945-, Césaire intentaba impulsar un movimiento local abierto al exterior y revertir la situación de vacío cultural de la isla. En la "Presentación" del primer número afirmaba: "Nada de ciudad. Nada de arte. Nada de poesía. Ni un germen. Ni un brote. O bien la lepra repugnante de las imitaciones. Verdaderamente, tierra estéril y muda." (1994, No 1: 5). Césaire no exageraba. Publicada

durante la Segunda Guerra, la revista no sólo fue afectada por la censura

5 Cahier d'un retour au pays natal/Memorandum on My Martinique, New York, Brentano's, 1947.

122


del régimen del almirante Robert (la derecha de Vichy), sino por una situación extrema de aislamiento. Como recordaría el martiniqueño, no tenían "ningún vínculo con nada en lo absoluto". Era casi imposible enriquecerse de la literatura contemporánea extranjera, especialmente de los más cercanos aportes antillanos y americanos: "No teníamos textos; no nos llegaba nada de Francia; los libreros de la Martinica eran en extremo pobres (...) Cuando por casualidad llegaba un periódico de Estados Unidos o de Francia, o cuando pasaba un viajero, nos precipitábamos sobre él..." (Leiner, 2008 [1975]: 381-382). Las condiciones eran tan desfavorables que, como resultado, los vínculos eran los determinados por la lógica de los circuitos coloniales. En efecto, Breton se topaba con Tropiques cuando, huyendo de la ocupación nazi al exilio en Nueva York, y desembarcado junto con André Masson y el cubano Wifredo Lam (quien fue detenido) en la Martinica, recorría Fort-de-France -como se informaba en las "Novedades" del № 2 (julio de 1941). ${ }^{6}$

Césaire, sin embargo, entonces profesor de literatura en el Liceo Schœlcher, agrupaba a sus colegas "con buena voluntad", entre los que se contaban su esposa Suzanne Césaire y quienes habían colaborado en Légitime Défense: René Ménil, Aristide Maugée. "¡Éramos muy pocos y había una terrible falta de co-la-bo-ra-do-res!" (Leiner, 2008 [1975]: 379-380). Césaire y Ménil, sin duda las voces más interesantes del grupo, aprovechaban sus "posiciones estratégicas" como profesores para incitar a sus alumnos a la actividad intelectual ("tuve una influencia innegable sobre toda una generación", admitiría el martiniqueño) y hasta incorporarían sus colaboraciones. (Leiner, 2008 [1975]: 385). Al igual que antes en L'Étudiant noir, aunque ahora decididamente orientado a la realidad martiniqueña, Césaire promovía una toma de consciencia de la negritud de las Antillas mediante la rehabilitación de las raíces africanas de la cultura, una recuperación no exenta de cierto romanticismo, pero que resultaba revolucionaria porque develaba al negro históricamente oprimido y esclavizado y, reivindicando su identidad, intentaba revertir el secular complejo de inferioridad: "Quería despertar, quería llevar a la reflexión, quería suscitar. Creo que en mi acción cultural (el término aún no estaba de moda) la palabra clave fue: suscitar, hacer nacer." Y era, ciertamente -y de allí la importancia de Tropiques- "la primera vez que una empresa así se llevaba a cabo de ma-

6 También Breton en su ensayo sobre Césaire (publicado originalmente como "Martinique charmeuse de serpents. Un grand poète noir" en el No 11 de 1944), relataba el hallazgo 'azaroso' del primer número de Tropiques, expuesto en la mercería de la hermana de René Ménil, quien lo condujo luego al encuentro con los responsables de la revista. 
nera continua, de manera perseverante." (Leiner, 1993 (t.1): 131-132). Suzanne Césaire divulgaba desde el $N^{\circ} 1$ la etnografía de Frobenius descubierta en París, el No 5 reproducía un extracto de su Histoire de la civilisation africaine, así como un artículo del 8-9 abordaba "La trata de negros"; en el último (13-14), de 1944, se reproducía un discurso de Césaire sobre la abolición: su "Homenaje a Victor Schølcher". Esa negritud desafiante era vehiculizada en la propia producción poética de Césaire, que ocupaba un lugar central en la revista, y explicaba además su afiliación con los "Poetas negros americanos" (James Weldon Johnson, Toomer, Claude McKay), quienes eran introducidos por el martiniqueño en el $N^{\circ} 2$, y cuyos poemas se publicaban en traducción. Pero, una vez más, la falta de colaboradores y de vínculos con otras revistas eran notables. A pesar de los esfuerzos, Tropiques incluía más literatura francesa (Péguy, Lautréamont, Rimbaud, Mallarmé y, especialmente después del encuentro con Breton, ensayos sobre el Surrealismo ${ }^{7}$ ) que la que hubiera sin duda deseado, teniendo en cuenta su objetivo de reivindicación de la identidad afro-antillana.

Había en el grupo una firme voluntad de educar a sus lectores en el reconocimiento de su especificidad local, de recuperar la historia, el folclore, incluso la flora y la fauna de la Martinica. Ese programa era explicitado al comienzo del $N^{\circ} 3$ (oct. 1941): "Narciso martiniqueño ¿dónde, pues, te reconocerás? Sumerge tus miradas en el espejo de lo maravilloso: tus cuentos, tus leyendas, tus cantos. Allí verás inscribirse, luminosa, la imagen segura de ti mismo" (Césaire, 1994, № 3: 7). A partir de ese número, posterior al encuentro con Breton, la revista revelaba por cierto la mayor 'seguridad' de sus propios animadores, especialmente de Césaire, respecto de los modos operativos de una literatura antillana: se afiliaban resueltamente con el Surrealismo como vía de desalienación, como mecanismo de exploración del "ser profundo", la identidad negra, el inconsciente africano. Para Césaire, la vinculación con Breton resultó tan clave como su anterior encuentro con Senghor: "literalmente, fue un flechazo. Qué suerte extraordinaria. (...) no nos separamos por un mes y aquello que los libros habían comenzado y bien, la amistad, la

7 Era especialmente Ménil quien ofrecía varios ensayos sobre el surrealismo y evaluaba las posibilidades de una literatura antillana basada en la identidad negra, en la apropiación de nuevas técnicas (que incluían las del jazz) y nuevos conocimientos científicos: etnografía, materialismo histórico, psicoanálisis. En "Situation de la poésie aux Antilles" (publicado en el mismo $\mathrm{N}^{\circ} 11$ que incluía el texto de Breton sobre Césaire), Ménil denominaba al nuevo movimiento "Romantisme antillais", o "la nueva concepción de la belleza créole"; y destacaba la tarea precursora de Légitime Défense en París y el liderazgo de Césaire.

(24)


viva amistad, en fin, por el contacto humano y me vuelvo un surrealista francés. Pero manteniendo la mente muy en claro. Nunca me dejé ahogar en la literatura." (Maunick, 1976). Breton no hacía más que confirmar las búsquedas de Tropiques: así, pues, comenzaba la exploración de lo 'maravilloso' antillano. En este sentido, lo más valioso fue sin duda la "Introduction au folklore martiniquais" ( $\left.\mathrm{N}^{\circ} 4\right)$, donde Césaire y Ménil presentaban, desde una mirada fuertemente ideológica y alejada de todo exotismo, algunos cuentos 'créoles' recogidos por Lafcadio Hearn y Gratiant. ${ }^{8}$

Las búsquedas de Tropiques, empero, no resultaban novedosas en el contexto antillano si se tiene en cuenta que en la también francófona Haití se emprendía esa tarea de rehabilitación de la cultura popular desde hacía más de una década. Mientras los haitianos venían estableciendo contactos con los cubanos (Jacques Roumain con Nicolás Guillén, por ejemplo), y Carpentier ya había aliado la práctica surrealista a la exploración de la cultura afrocubana, Tropiques, hasta el encuentro con los "desembarcados" en la Martinica, no precisaba su programa del "maravilloso antillano". Sería a partir de entonces que Césaire dejaría de ocultar las influencias del Surrealismo, y, más seguro de sus asimilaciones, insistiría en la validez de la apropiación del mismo en función de la Negritud, mientras su esposa Suzanne escribía "la poesía martiniqueña será caníbal o no será" (1994, N 4: 50). En el No 5 publicaba Césaire un texto dedicado a Breton: "En guise de manifeste littéraire", el cual sería incorporado a las nuevas ediciones del Cahier d'un retour au pays natal desde 1947. Allí la operación era explicitada: "Porque los odiamos, a ustedes y a su razón, reivindicamos la demencia precoz, la locura llameante, el canibalismo tenaz"; bajo la "membrana vitelina" que separaba al yo lírico de su yo profundo, hablaban los "Hougans. Hougans sobre todo", cuyos demonios no olvidaban "a los del barco negrero". Luego del "manifiesto", un texto de Aristide Maugée celebraba precisamente a Césaire como "Poeta de las más vertiginosas metafísicas. Pero también poeta negro", pleno de la magia del sonido y del ritmo, "elemento negro por excelencia" ("Aimé Césaire, Poète", No 5: 17-18).

8 El análisis de los cuentos destacaba en ellos el motivo del hambre, del miedo y de la derrota, frente a los cuales las figuras míticas (centrales en la cultura popular antillana) del Colibrí y del Conejo ("Compadre Conejo"), este último símbolo de la astucia individual, reflejaban para Césaire y Ménil que "Las soluciones individuales reemplazan las soluciones de masa. Las soluciones de artimaña reemplazan las soluciones de fuerza” (1994, N4 (enero 1942): 10). El planteo motivará una de las más agudas reflexiones de Glissant en El discurso antillano (1981), en el ensayo "Poética natural, poética forzada". 
Pero, además, Tropiques, desde el encuentro con Breton, Masson y "el sorprendente pintor negro cubano" Wifredo Lam a quien saludaban en las "Nouvelles" del No 2 (sección que junto con la "Revue de Revues" se inauguraba allí) afirmaría su voluntad de religación con movimientos literarios y artísticos afines. Apenas unas pocas colaboraciones fueron importantes en este sentido, lo cual confirma que, al fin y al cabo, Tropiques publicaba lo que podía; algo evidente cuando se observa la ausencia general de referencias a figuras centrales del canon latinoamericano, mientras en el $N^{0} 3$ en la sección "Relire", se reproduce un fragmento del peruano Ventura García Calderón (sobre Francia) entre otros de Breton, Eugenio d'Ors, Flammarion y Leonardo Da Vinci. Lo que allí (sin duda involuntariamente) terminaba siendo una suerte de cadáver exquisito de citas encontradas en los pocos libros disponibles, en la sección "Revue de Revues" se volvía una tarea más organizada, pues implicaba la traducción: se publicaba una "Lettre Vénézuélienne" donde se comentaba un "pequeño libro del Sr. Durand", 9 cuyo mérito era plantear la siguiente cuestión:

¿Estableceremos, sí o no, relaciones culturales sostenidas con nuestros vecinos americanos y españoles? Urgencia tanto más real en tanto nuestros problemas son frecuentemente los mismos.

Mismas dificultades encontradas. Mismas soluciones propuestas.

Países coloniales o semi-coloniales, países que se buscan.

Culturas que a través de las pseudomorfosis tienden a afirmar su originalidad propia. Y en esa fiebre, de pie, allá, "el nuevo Indígena”, aquí, el nuevo Negro. (1994, No 3: 52).

El artículo comentaba el aporte del "criollismo" o "nacionalismo" de la literatura venezolana (como Doña Bárbara de Gallegos), y si se agregaba "un Pablo Neruda, un César Vallejo, un Miguel Ortera (sic) Silva", podía afirmarse que "la epopeya americana apenas ha comenzado". Este breve texto era seguido de la traducción de un artículo publicado en la revista venezolana Viernes (en 1940) sobre los poetas "viernistas". ${ }^{10}$ La sección, por último, traducía un texto de la revista Life sobre el cine y el Surrealismo.

9 Dado que no se ofrece ningún dato del "pequeño libro" (ni su título, ni el nombre completo o nacionalidad del "Sr. Durand"), es difícil afirmar si se establecían lazos directos con los venezolanos.

10 Los puntos centrales sobre los "viernistas" eran resumidos didácticamente al final, donde se discutía su afiliación al surrealismo con reservas, para Tropiques índice del "miedo de no ir hasta el fondo". ( $\mathrm{N}^{\circ}$ 3: 59)

126 
Todo este material, podemos especular, quizá había sido arrebatado de las manos de aquellos viajeros que pasaban por Fort-de-France. ${ }^{11}$ No cabe duda de que, a juzgar por lo afirmado en la sección "Revue de RevuesCorrespondances" del número 6-7 (febrero de 1943), los contactos con Breton, Masson y Lam, estratégicos para fortalecer redes intelectuales con los cubanos y con los surrealistas exiliados en Nueva York y México, daban sus frutos. Se comenzaba repitiendo el programa del número inicial -"Nada de ciudad. Nada de arte. Nada de poesía..." etc.- para agregar:

Así Tropiques ve las Antillas en 1941. No se trata ya de "cruzarse de brazos, en la actitud estéril del espectador", sino de modificar su destino. ¿Nuestra misión? Participar, nosotros también, en el concierto del mundo. (...)

(...) nuestra voz no careció de eco: puesto que el espíritu renace en la juventud presente con la promesa del comienzo.

Puesto que Tropiques ha recibido en el extranjero una mayor audiencia aun que en las Antillas.

Puesto que grandes voces amigas nos expresan su afecto y simpatía, más allá del mar Caribe, en Cuba, Curaçao, México, Nueva York. (Césaire 1994, Nº 6-7: 59)

Además del anuncio de una antología que Benjamin Péret preparaba en México sobre "Mythes, légendes et contes populaires d'Amérique", se informaba que en Cuba se había publicado, en traducción de Lydia Cabrera, el Cahier d'un retour au pays natal, ilustrado por Lam y con prefacio del mismo Péret (que reproducían), donde el surrealista saludaba al "primer gran poeta negro que ha roto todas las amarras..." ( $N^{\circ}$ 6-7: 60). Se presentaba luego un artículo de José Pierre (mano derecha de Breton) sobre Lam, cuya obra se asociaba con los "gritos desgarradores" y "llamados sordos del tam-tam" de Césaire (№ 6-7: 62). También se comentaba el "Prolegomènes à un 3e manifeste du surrealisme ou non" de Breton y su "magnífica realización": la revista que dirigía en Nueva York -sin duda VVV (1942-1944), difusora del Surrealismo durante la Ocupación y con la cual Césaire colaboró, al igual que lo hizo con

11 Las "Nouvelles" del N 4 evidencian, a su vez, la ansiedad de contactos directos con Haití. Allí se informaban tres eventos: "Fundación en Port-au-Prince de un Instituto de Etnología-icuándo veremos allí a becarios martiniqueños?", se preguntaban. (Se trataba claramente del Instituto fundado por Price-Mars en 1941). Luego se anunciaba "un congreso afro-americanista" en enero de 1942 en Port-au-Prince. Finalmente, una exposición y conferencia de André Masson en el Museo Baltimore de Estados Unidos. 
Hémisphères. Revue franco-américaine de poésie (1943-1945), el otro órgano neoyorkino del surrrealismo donde se publicó el ensayo de Breton sobre Césaire ( $\left.N^{\circ} 2-3,1943-1944\right),{ }^{12}$ y donde también participaron Masson, Lam y Nicolás Guillén, entre otros. Hémisphères, dirigida por Yvan Goll, era elogiada en Tropiques en la sección "Les revues" del N 11 (mayo 1944), especialmente por su número 2-3 consagrado "casi exclusivamente a las Antillas". Además del "Descubrimiento de Tropiques", Goll abordaba allí la poesía "mestiza", afrocubana, de Guillén, que se presentaba junto con la de Emilio Ballagas, y Tropiques reproducía sus opiniones, ciertamente auspiciosas para la literatura antillana.

Lo que sin duda se extrae de todo lo anterior es que, a pesar de la ansiedad de influencias americanas y antillanas (incluso africanas), los lazos más importantes -y más provechosos para la carrera de Césaire-los establecía Tropiques con los metropolitanos (se sumaría Étiemble, cuya conferencia en Fort-de-France contra la ideología de Vichy se reprodujo en el $\mathrm{N}^{0} 11$ ). Dado el aislamiento de la isla, era paradójicamente gracias a los contactos con los surrealistas franceses, especialmente con Breton, como los martiniqueños se religaban con los latinoamericanos o antillanos. Un claro y curioso ejemplo de esto es la publicación, en el No 8-9 (octubre de 1943), de un poema en versión bilingüe de Jorge Cáceres, junto con Braulio Arenas -como se informaba- "unos de los jefes del grupo surrealista chileno". La conexión evidentemente se establecía a través de la revista neoyorquina de Breton: ambos chilenos colaboraron en VVV, y a su vez, la revista del grupo Mandrágora Leitmotiv: Boletín De Hechos E Ideas (1942-1943), dirigida por Arenas, publicó entre otros textos de los franceses la traducción del "Prolegomènes..." de Breton. En el No 2, de diciembre de 1943, el chileno reproducía en Santiago un poema de Césaire "Colombes bruissement du sang". El año anterior, también vía Breton, Roger Caillois, otro de los exiliados franceses en América, reseñaba un poema de Césaire en la revista Lettres françaises que dirigía en Buenos Aires. ${ }^{13}$ Fue esta, sin duda, la primera recepción

12 Cuando se reproduce en el No 11 (mayo de 1944) de Tropiques se anuncia que constituiría el prefacio al Cahier a publicarse próximamente en "Éditions Hémisphères" (lo cual no sucedió ya que fue editado, como apuntamos en la nota anterior número 5, tres años más tarde por Brentano's).

13 Caillois, cofundador con Bataille y Leiris del Collège de Sociologie, se refugió en Buenos Aires a instancias, como se sabe, de Victoria Ocampo, quien fundó y financió la revista de Caillois. En contacto con los surrealistas, en cuyas revistas neoyorkinas colaboró, Caillois a su vez publicó sus contribuciones en Lettres françaises. En el No 3 (enero 1942) reproducía "Le Dialogue Créole" de Breton y Masson, parte de lo que constituiría el posterior "Martinique, charmeuse de serpents. Un grand poète noir". 
sudamericana del martiniqueño. Es difícil saber si por entonces Césaire mantenía un contacto directo con Caillois, pero estaba sin duda al tanto de su revista bonaerense y de algunas de sus opiniones, que le eran contrarias. ${ }^{14}$ (Unos años más tarde, Césaire arremetería contra Caillois en su beligerante "Discurso sobre el colonialismo").

Además de esta intricada red de contactos mediados por el Surrealismo francés, en los últimos números se evidenciaban vínculos más directos con quienes Tropiques compartía más intereses: los cubanos inclinados al rescate de la cultura afro-antillana, y, de modo general, quienes señalaban "mismas dificultades encontradas" y "mismas soluciones propuestas", como Tropiques había afirmado en relación con la literatura latinoamericana. Por eso, en el No 10 de febrero de 1944, Césaire introducía un cuento de Lydia Cabrera que se reproducía en traducción, y en el No 12 de enero de 1945, en la sección "Revue de Revues", se publicaba el ensayo "L'évolution culturelle de l'Amérique Latine" de Alejo Carpentier, extraído de la revista haitiana Cahiers d'Haïti (de enero de 1944). Ese breve panorama resultaba informativo tanto como claramente valioso a los ojos de Césaire. Allí, Carpentier, al referirse a cómo Rubén Darío había encontrado en los modelos de Francia los medios para revolucionar el español, afirmaba, por ejemplo, que "conocer no es sinónimo de imitar" ( $\mathrm{N}^{\circ} 12$ : 219). Luego se reproducía, del número de marzo de 1944 de los Cahiers d’Haïti, "Le Panorama haitien", un breve artículo del francés Pierre Mabille,

14 La consulta de la correspondencia de Césaire (aún inaccesible) sin duda echaría luz sobre los contactos que el martiniqueño establecía, así como la publicación de las cartas de Breton (especialmente las intercambiadas con Césaire y Caillois), anunciada para el año 2016, servirá para profundizar el estudio de estas relaciones. No hemos podido consultarlas donde hoy se conservan (Biblioteca Jacques-Doucet, París). El investigador Alex Gil (2011), quien sí lo ha hecho, señala que en algunas cartas dirigidas a Breton en 1944 Césaire critica a Caillois, después de haber leído sus opiniones sobre poesía en Hémisphères (enero 1944). Gil, quien también consultó la bonaerense Lettres françaises, señala que es en el No 6 (noviembre de 1942), en el cual Caillois reseña el primer número de VVV (junio 1942), donde comenta el poema de Césaire "Conquête de l'Aube" y se refiere a su "notable poder lírico desafortunadamente debilitado por el empleo de numerosos adjetivos demasiado automáticamente poéticos, del tipo: extático, maravilloso, sonámbulo, convulsivo, incendiario, etc.". A su vez, en el $\mathrm{N}^{\circ} 15$, en una reseña del No 35 de la revista Fontaine -órgano fundado en 1939 por la Resistencia intelectual francesa en Argelia-, donde aparecía también "Un grand poète noir" de Breton y el poema "Batouque" de Césaire, Caillois criticaba que los textos, al contrario de lo anunciado, no fueran inéditos. Gil considera que Césaire nunca tuvo en sus manos los números de Lettres françaises, aunque probablemente establecía por entonces una correspondencia con su director, ya que en carta a Breton de abril de 1945, Césaire le informa que recibió por correo un ejemplar de Les impostures de la poèsie de Caillois. Más tarde, y (por lo que se infiere de todo lo anterior) después de leer el texto de Breton consagratorio de Césaire, Caillois publica en el $N^{\circ} 16$ de Lettres françaises (abril 1945) un poema del martiniqueño, casi idéntico al publicado en el № 11 de Tropiques (mayo 1944) que luego integraría Et les chiens se taisaient, el "Oratorio lyrique" de Les Armes miraculeuses (1946). 
de quien se publicaba, además, un extenso y valioso ensayo sobre Wifredo Lam, que incluía el relato de una ceremonia del vodun haitiano. ${ }^{15}$

Se podría pensar, incluso, que la religación que promovía la Negritud de Césaire y el creciente uso de figuras y mitos caribeños y especialmente haitianos, servía no sólo a la reivindicación identitaria sino también para contrarrestar simbólicamente el sentimiento de aislamiento cultural sufrido en las islas por entonces. El Cahier ya había sentado las bases de un imaginario poético común a las Antillas, cercano no sólo a América, sino también a África, y especialmente a "Haití donde la negritud se puso de pie por primera vez y dijo que creía en su humanidad..." (Césaire 1969: 52). ${ }^{16}$ Ubicado en ese mapa, Haití se volvía para el poeta un verdadero polo de religación simbólica. Era la Revolución haitiana, además, un poderoso núcleo de sentido en el imaginario caribeño. A partir de su estadía en Haití, Césaire no solo comenzaba a establecer contactos más estrechos y más directos con los intelectuales haitianos (caso de René Depestre) y a afianzar sus vínculos con Cuba, sino a incorporar a su obra la mitología de la Revolución haitiana y a explorar problemas y temáticas comunes al espacio antillano. Esto, que acentuaba el "particularismo" siempre buscado por Césaire, para asegurar una poética diferenciada de los modelos centrales (del mismo modo en que Tropiques, con su teorización del "maravilloso" terminaba participando en la estructuración de una estética caribeña), religaba su obra con la de intelectuales con preocupaciones comunes. Con su temprano Y los perros callaban (1946), basado en la Revolución haitiana, su incursión en la historiografía antillana con su ensayo Toussaint Louverture. La Revolución Francesa y el problema colonial (1960) y en el teatro, con La tragedia del Rey Cristophe (1963), Césaire anudaba crecientemente su obra con la de aquellos antillanos que exploraban el 'mito haitiano'. ${ }^{17}$

15 Césaire sin duda había accedido a todo este material durante su estadía de seis meses en Port-au-Prince en 1944, donde, invitado por Mabille (agregado cultural de la Embajada de Francia) había participado en el Congreso Internacional de Filosofía. Tropiques reproducía en el mismo No 12 su conferencia allí dictada, "Poésie et connaissance", donde Césaire se afiliaba explícitamente con el Surrealismo.

16 Algunos versos más adelante, el poeta del Cahier hacía suya, además, la figura del revolucionario Louverture, y con mayúsculas: "TOUSSAINT, TOUSSAINT LOUVERTURE" (1969: 54).

17 Césaire seguía además las ideas del trinitario C.L.R. James sobre la revolución en Toussaint Louverture (cfr. Figueroa 2009). El ensayo de James había sido traducido por Pierre Naville como Les Jacobins noirs. Toussaint Louverture et la Révolution de Saint-Domingue, en 1949, para Gallimard. En 1960 Price-Mars publicaba a su vez Silhouettes de nègres et de négrophiles en Présence Africaine, donde abordaba las figuras de Toussaint, Christophe y Dessalines. Es muy probable que Césaire a esta altura conociera asimismo El reino de este mundo de Carpentier, también traducido por Gallimard (1954), para la colección La Croix du Sud dirigida por Caillois.

10


A su vez, desde Las armas milagrosas, donde apareció Y los perros callaban, hasta la década del 60, Césaire se adscribió resueltamente al Surrealismo al tiempo que acentuó su diferencia. Porque precisamente su consagración -tanto en las Antillas como en la Metrópolis- una vez finalizada la Segunda Guerra, estaba fuertemente vinculada con el modo en que el martiniqueño, vía Negritud, ingresaba a la "literatura universal". El mismo Césaire se preocupaba por enfatizar este aspecto: era el "particularismo" antillano lo que lo distinguía del Surrealismo metropolitano. Sobre su poesía explicaría: "quería servirme del surrealismo como de un arma, permaneciendo fiel a la negritud" (Beloux, 1969: 28). En Las armas milagrosas, donde publicaba varios poemas anteriormente aparecidos en Tropiques y el "Oratorio lírico" (también anticipado en la revista) Et les chiens se taisaient, la figura del Rebelde era claramente deudora de su descubrimiento del valor simbólico del mito revolucionario haitiano. Era esta una 'tragedia' lírica, alegórica, muy diferente de los dramas posteriores de los años 60. Pero estaba allí en germen, en la figura de ese mártir, el 'Rebelde', y en el tema central de la revuelta contra la opresión, la problemática de la descolonización que aparecería luego en su tríptico teatral -La tragedia del Rey Cristophe (1963), Una temporada en el Congo (1966) y Una tempestad (1969)-, tanto como el impulso religador de una Negritud comprometida con todos "los condenados de la tierra": "No hay en el mundo un pobre tipo linchado, un pobre hombre torturado, en quien no sea yo asesinado y humillado" -dice el Rebelde (Césaire, 1946: 135-136).

Cuando Césaire ofrece, en su entrevista con Leiner, una mirada retrospectiva de su obra poética, desde sus comienzos hasta los años 60, en relación con la Negritud, afirma que, mientras el Cuaderno de un retorno al país natal "es el poema de la toma de conciencia, y la delimitación del dominio", Les Armes miraculeuses (1946) y quizá aún más Soleil cou coupé (1948) y Corps perdu (1950) son "la exploración en profundidad de ese dominio", una tarea que termina con Ferrements (1960) y Cadastre (1961) - de hecho, es este poemario una reedición y revisión parcial de poemas previos. Ferrements, en este recorrido, fue "un balance provisorio" (Leiner, 1993 (t.1): 137-138). Efectivamente, se podía encontrar tanto en Cadastre como Ferrements una tendencia hacia un lenguaje más conciso y un cierto abandono de las imágenes surrealistas y exploratorias de los poemas iniciales, pero era cierto que Césaire había forjado su poética de todos esos años en ese dominio claramente delimitado tanto por el Surrealismo como por la Negritud. Incluso Ferrements, desde su título, aludía tanto al hierro con que se había encadenado a los esclavos como a los "fermentos" libertarios. Era 
ese el "particularismo" que afiliaba las Antillas al África, y que había servido, precisamente con el inicio del proceso de descolonización mundial, a la consagración de los poetas negros, a la canonización de Césaire. Esto implicaba que el martiniqueño captaba lectores entre los colonizados y en la Metrópolis; alcanzaba, como señala Gregson Davis, una "notable doble recepción". El crítico piensa aquí en el modo en que el escritor se convertía en una de las voces de la emancipación más reconocidas por los negros francófonos, a la par que, a los ojos de los europeos, resultaba un participante clave de la estética vanguardista (Davis, 2008: 112). Sin embargo, como ya apuntamos, la oportunidad de la obra de Césaire no hubiera sido tal sin el apoyo de sus amistades metropolitanas desde su encuentro con Breton. Con el fin de la segunda guerra, y el ingreso de Césaire en la política que lo llevaría a ser elegido como alcalde de Fort-de-France y Diputado en la Asamblea Nacional (al igual que Senghor y Damas), su presencia en la metrópolis facilitaba su participación, nuevamente, en París, donde volvían a encontrarse africanos y antillanos y donde la intelectualidad de izquierda, en el clima eufórico de la Liberación, ocupaba el centro del campo literario. Como se sabe, era Sartre, especialmente desde su resonante conferencia de 1945 "El existencialismo es un humanismo", su figura clave. Si, según el ideal sartreano del compromiso al que tantos se plegaban, la adhesión al Comunismo podía reducir la autonomía del intelectual no solo en la cuestión estética (realismo socialista), sino en razón del privilegio marxista de la categoría de clase, Césaire se preocupaba por destacar el eje particular desde el cual se afiliaba al Partido. En el folleto de 1946 "Pourquoi je suis communiste" del PCF, donde se recogían las declaraciones de sus adherentes más célebres (Anatole France, Barbusse, Aragon, Éluard, Ponge, Tzara, Picasso, etc.), afirmaba:

He adherido al Partido Comunista porque, en el mundo mal curado de racismo donde persiste la explotación feroz de las poblaciones coloniales, el Partido Comunista encarna la voluntad de trabajar efectivamente para el advenimiento del único orden social y político que pudiéramos aceptar -fundado en el derecho a la dignidad de todos los hombres sin distinción de origen, de religión ni de color. (Césaire, cit. en Hale, 1978: 262)

Mientras en estos años Césaire participará en cantidad de encuentros de escritores "comprometidos", su escritura adquirirá un creciente capital simbólico con la legitimación de figuras como la de Sartre. Porque, además de los Prefacios que este escribe en apoyo a los poetas y revolu- 
cionarios anticolonialistas, ${ }^{18}$ también desde su revista Le Temps modernes (creada en 1945) y con su participación en Présence Africaine, la revista fundada en 1947 y dirigida por el senegalés Alioune Diop, ${ }^{19}$ auspicia la escritura de la Negritud. Que en el caso particular de Césaire el apoyo de Sartre no fue un aspecto menor en su consagración, lo demuestra el pasaje siguiente de la carta que el senegalés le dirigía a Sartre en 1958, cuando su editorial ya había publicado varias obras de Césaire (como su famoso Discurso sobre el colonialismo, 1955) y esperaba contar con una nueva colaboración del francés:

no se sorprenderá de que nos dirijamos nuevamente a usted para que una voz autorizada (la más autorizada quizá en Occidente) se alce para hablar de Aimé Césaire, poeta de la negritud. Césaire, lo sé, no lo desea. Piensa que su producción no es todavía suficiente (...).

Pero los africanos esperan. Han leído y releído y llevado bien alto en sus corazones las estrofas del Cuaderno, de las Armas o los períodos del Discurso. Esperan como un eco. Usted, ustedes los occidentales, detentan todavía (a pesar del esfuerzo que personalmente desde hace tantos años usted despliega contra el racismo y el colonialismo), la autoridad de la cultura. Todo el mundo está habituado a amar una obra y a buscar en sus declaraciones el eco de su amor. Hable, pues, a fin de que se realice más rápidamente nuestro acceso (el acceso de nuestra consciencia y de nuestra iniciativa) a los recursos técnicos y políticos de la vida cultural, en fin, de la vida moderna. (Diop, en Frioux-Salgas, 2009: 12). ${ }^{20}$

Césaire, sin embargo, había adquirido a esta altura suficiente visibilidad entre las figuras más progresistas de Europa -en 1949 Aragon lo

18 Entre otras actividades de apoyo a las causas 'tercermundistas', Sartre escribe en 1957 el Prefacio al Portrait du colonisé, précédé du portrait du colonisateur del tunesino Albert Memmi, un ensayo clave, junto con el Discurso sobre el colonialismo de Césaire, Piel negra, máscaras blancas y Los condenados de la tierra de Fanon, de los discursos anticolonialistas de la época.

19 Diop promovía fuertemente los vínculos con la vanguardia intelectual de la época. El comité asesor de Présence Africaine incluía, además de Sartre, a André Gide, Albert Camus, Richard Wright, Leiris, Senghor y Césaire; así como a agentes del mundo editorial hospitalario a la escritura de las colonias -Seuil (Emmanuel Mounier), Seghers, Corréa (Maurice Nadeau), Maspéro. (Frioux-Salgas, 2009: 11).

20 Ignoramos cuál era el pedido específico de Diop a Sartre, quizá un prefacio para incorporar a la reedición de alguna obra de Césaire ya publicada, como el Discurso sobre el colonialismo (que tuvo varias en Présence Africaine) o el Cahier (en 1956, la editorial ya había realizado una nueva edición). Más tarde, en 1971, publicó una nueva, en versión bilingüe, con traducción de Émile Snyder y el prefacio de Breton. Fue esta edición la que obtuvo mayor recepción por fuera del circuito francófono. 
presentaba como uno de los más grandes poetas políticos de la época, junto con Neruda y Maiakowski (Hale, 1978: 310), en 1950 su poemario Corps perdu era ilustrado por Picasso, y sus variadas intervenciones, tanto en la Asamblea Nacional como el mundo intelectual, tenían repercusión. Asegurado en el compromiso sartreano, Césaire produce en esos años sus discursos más estridentes y comienza a discutir de igual a igual con el canon intelectual francés, señalando la complicidad de la Francia "humanista" con el colonialismo y comparando a su vez el colonialismo francés con el nazismo. ${ }^{21}$ En este contexto, se destacaría su resonante Discurso sobre el colonialismo (1950), el cual, desde su publicación en Présence Africaine en 1955, ${ }^{22}$ se convirtió en uno de los clásicos de la literatura anticolonialista y fue ampliamente difundido. Allí Césaire, con un gran manejo de la retórica política, se dedicaba a impugnar de la tradición francesa precisamente a aquellas voces que ahogaban los comienzos de los colonizados: Ernest Renan, Joseph de Maistre, Jules Romains, recientemente elegido miembro de la Academia Francesa, "profeta de la Revue des Deux Mondes", y quien ofrecía una "comparación idiota" como la siguiente: "La raza negra todavía no ha dado, no dará jamás un Einstein, un Stravinsky, un Gerschwin" (Césaire, 2008: 330). ${ }^{23}$

Por entonces, sin embargo, el proyecto de Césaire elaborado desde sus comienzos - el de impulsar y dar visibilidad a la producción antillana de los negros colonizados-, era apoyado por otro de sus amigos metropolitanos. Michel Leiris, reconocido desde L’Afrique fantôme (1934), uno de los editores de Le Temps modernes, y quizá el primer etnógrafo

21 Césaire se afiliaba sin duda con Sartre y su desmantelamiento del anti-semitismo europeo en Reflexiones sobre la cuestión judía (1946), llevando el planteo a sus últimas consecuencias al señalar cómo el "nazismo" practicado por Francia en las colonias tampoco había incomodado a sus más ilustres pensadores.

22 El "Discurso" que, de hecho, no fue leído en público, tuvo una primera versión en 1950 en Réclame, antes de su más difundida (y ampliada) edición de 1955 en Présence Africaine.

23 Como mencionamos, otro de los querellados aquí era Roger Caillois, sin duda más cercano al círculo de Césaire -por ello, quizá, lo criticaba in extenso. Caillois, decía, había emprendido una cruzada contra "la gran traición de la etnografía occidental" que ponía en duda "la superioridad omnilateral" de Europa (2008: 345). Esos intelectuales europeos que según Caillois renegaban de su cultura (entre los cuales debían encontrarse amigos de Césaire como Michel Leiris), solo habían desmentido la idea de la inferioridad y el primitivismo de las culturas nooccidentales. Lo peor, para Césaire, era que Caillois quisiera salvar a Occidente reivindicando su moral mientras "tantos valerosos hijos de Occidente, en el claroscuro de los calabozos, prodigan a sus hermanos inferiores de África, con tantos e infinitos cuidados, estas auténticas marcas de respeto a la dignidad humana que se llaman, en términos técnicos, "la bañera", "la electricidad" y "el cuello de botella". (2008: 348) 
que analizaba el lugar central del colonialismo en su propia disciplina, ${ }^{24}$ publicaba en 1955 el citado Contacts de civilisations en Martinique et en Guadeloupe. Césaire, a esta altura, ya había adquirido suficiente capital simbólico como "gran poeta negro" y era reconocido como intelectual más allá de los espacios francófonos. Ahora, además, uno de esos franceses cuya actividad se enriquecía a través de sus vínculos directos con los "colonizados" no solo apoyaba su causa anti-colonialista, sino que colaboraba, como el mismo Césaire celebraría, ${ }^{25}$ con la afirmación de la cultura antillana.

\section{Conclusiones}

El repaso por la trayectoria de Césaire, especialmente desde sus inicios como un joven estudiante negro en París, no hace más que confirmar la dificultad de los comienzos en condiciones socio-económicas y culturales de dependencia. Su recorrido, en efecto, ejemplifica los avatares a los que se encontraron sometidas las carreras de tantos intelectuales periféricos que en el siglo XX reclamaron un lugar en la "república mundial de las letras" o, mínimamente, anhelaron desarrollar sus vocaciones literarias. Césaire logró finalmente, luego de una formación metropolitana y con el apoyo de la intelectualidad progresista y anticolonialista europea, ser emparentado con "los grandes líricos franceses", como se afirmaba en el estudio de Leiris. Su amigo acudía allí, de hecho, al mismo argumento legitimador usado tempranamente por Breton y Sartre: Césaire se había apropiado de las "armas" liberadoras del Surrealismo en función de su Negritud, descubriendo incluso en el movimiento francés una ayuda psicológica para superar el complejo de inferioridad de los negros y reivindicar su identidad 'auténtica' (2008: 99 y ss). Era imprescindible para los colonizados, como se ve, comenzar estableciendo tanto las autoridades como las diferencias. Leiris, en su libro, destacaba precisamente la tarea meritoria de Tropiques: la reivindicación y el desarrollo de una cultura singular, sincrética, hecha de aportes africanos e indios, reactiva a la cultura blanca francesa implantada (2008: 106). Especialmente teniendo en cuenta la situación cultural "desoladora" en las Antillas, la actividad de

24 Especialmente en "L'etnographe devant le colonialisme", aparecido en 1950 en Le Temps modernes.

25 Sobre el estudio de Leiris (escrito luego de sus viajes a la región entre 1948-1952), Césaire afirmaría que fue "verdaderamente crucial": nadie antes había osado estudiar la cultura martiniqueña, "por primera vez, un francés, un etnólogo, explicitaba esa noción" (Leiner, 2003, t. 2: 43). 
Césaire como animador del grupo había sido fundamental. ${ }^{26}$ Los mismos elogios de Leiris, una vez más, confirmaban que los lazos más importantes -y más provechosos para la consagración de Césaire- los había establecido Tropiques con los metropolitanos. No obstante la ansiedad de influencias americanas y antillanas (incluso africanas), era aún la lógica del intercambio colonial la que determinaba comienzos y carreras intelectuales.

\section{Bibliografía}

Beloux, F. (1969). "Un poète politique: Aimé Césaire", Magazine Littéraire, No 34, nov. 1969, pp. 27-32.

Césaire, A. (1946). Les Armes miraculeuses. Paris: Gallimard.

(1969) [1939]. Cuaderno de un retorno al país natal (edición bilingüe). Prólogo y traducción al español de Agustí Bartra. México D.F.: Ediciones Era.

(2008). Para leer a Aimé Césaire, selección y presentación de Philippe Ollé-Laprune, México: Fondo de Cultura Económica.

et al. (1994) [1978]. Tropiques, 1941-1945. Collection complète. Entretien avec Aimé Césaire par Jacqueline Leiner, Lecture critique de Tropiques par René Ménil. París: Jean-Michel Place.

Davis, G. (2008) [1997]. Aimé Cesaire. Cambridge: Cambridge University Press.

Filostrat, C. (2010). Negritude Agonistes, Assimilation against Nationalism in the French-speaking Caribbean and Guyana. New Jersey: Africana Homestead Legacy Publishers.

Figueroa, V. (2009). "Between Louverture and Christophe: Aimé Césaire on the Haitian Revolution", The French Review, Vol. 82, No5, April 2009, pp. 1006-1021.

Frioux-Salgas, S. (2009). "Présence Africaine. Une tribune, un mouvement, un réseau", Gradhiva, 2009/2, No 10, pp. 4-21.

26 Leiris reconocía especialmente el logro de Tropiques en relación con la precariedad de condiciones materiales para el desarrollo cultural: "las causas económicas y sociales que, en la metrópolis misma, vuelven hoy una revista o un espectáculo de cierto tenor literario o artístico una empresa difícilmente rentable, son factores aun más fuertes en departamentos pobres como los dos departamentos antillanos y ellos por sí solos bastarían para explicar la dificultad que se encuentra en reunir un público" (2008: 96).

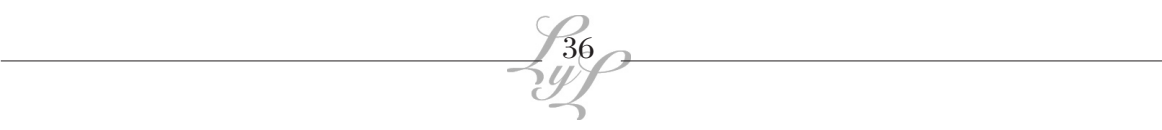


Gil, A. (2011). "The Inadvertent Poem: Césaire, Caillois and Lettres Françaises", versión digital: http://www.elotroalex. com/2011/01/the-inadvertent-fragment/

Glissant, E. (2005) [1981]. El discurso antillano, trad. de A. M. Boadas y A. Hernández, Caracas: Monte Ávila.

Hale, T. (1978). "Bibliographie commentée" [d’Aimé Césaire], Études françaises, Vol. 14, No 3-4, 1978, pp. 221-498. http://www.potomitan.info/cesaire/entretien_1976. php

Laroche, M. (1995). "El Caribe francófono" en Pizarro, Ana (coord.). América Latina: palavra, literatura e cultura. Vol. 3: Vanguarda e Modernidade (1995). Campinas, São Paulo: Unicamp, pp. 519-538.

Leiner, J. (1993-2003). Aimé Césaire. Le terreau primordial. Tome 1 (1993); Tome 2 (2003). Tübingen: Gunter Narr.

(2008) [1975]. "Conversación con Aimé Césaire", trad. de Yenny Henríquez, en Aimé Césaire 2008: 379-400.

Leiris, M. (2008) [1955]. Contacts de civilizations en Martinique et en Guadaloupe. Chicoutimi (Québec): J.-M. Tremblay. Versión electrónica, online: http://classiques.uqac.ca/ contemporains/leiris_michel/leiris_michel.html

Malela, B. B. (2008). Les écrivains afro-antillais à Paris (1920-1960). Stratégies et postures identitaires. Paris: Karthala.

Maunick, E. J. (1976). "Entretiens 1 \& 2 avec Aimé Césaire" (France Culture). http://www.potomitan.info/cesaire/entretien_1976. php

Rama, A. (1995). La ciudad letrada. Prólogo de Hugo Achugar. Montevideo: Arca.

Said, E. (1985) [1975]. Beginnings. Intention and Method. New York: Columbia University Press.

V.V.A.A. (1979) [1932]. Légitime Défense [Revue, n 1], Préface par René Menil. Paris: Jean-Michel Place. 